\title{
A new species of the genus Coelosia Winnertz from Tibet, China (Diptera: Mycetophilidae)
}

\author{
Jian Cao \& Zhiwei Huang
}

Cao, J. \& Huang, Z.W. 2016: A new species of the genus Coelosia Winnertz from Tibet, China (Diptera: Mycetophilidae). — Entomol. Fennica 27: 77-80.

A new species of the genus Coelosia Winnertz, 1863 from Tibet, China is described, figured and discussed. Coelosia tibetensis Cao \& Huang, sp. n. is the second Coelosia species from China. Two ocelli, clear brown shadings on the wing and the shape of the gonostylus are good characters to separate it from Coelosia tenella, the other Coelosia species found in China.

J. Cao, Chongqing Three Gorges Vocational College, Wanzhou, Chongqing 404155, China; E-mail: 407586199@qq.com

Z.W. Huang, Chongqing Three Gorges Vocational College, Wanzhou, Chongqing 404155,China; E-mail: hzwandcj@163.com

Received 29 January 2015, accepted 20 January 2016

\section{Introduction}

Coelosia Winnertz, 1863 (Diptera: Nematocera: Mycetophilidae) is a small genus with wide distribution. About 9 known species are from the Palaearctic and Oriental regions, but from China C. tenella (Zetterstedt, 1852) was the first recorded species in this genus in 1988 (Hackman et al. 1988).

In this paper, we report and describe a new species of the genus Coelosia from Tibet China. The specimens were discovered in the Insect Collection of Chongqing Three Gorges Vocational College, Wanzhou, Chongqing, P. R. China.

\section{Materials and methods}

The specimens were collected by sweep-netting and preserved in $80 \%$ alcohol. The genitalia were treated in the standard way (heated in a solution of $10 \% \mathrm{KOH}$, neutralized in acetic acid and washed in distilled water), and placed into glycerin for detailed study and later preserved in a microvial with glycerin. The morphological terminology used follows that of Søli et al. (2000).

\section{Taxonomy}

\subsection{Identification of the genus Coelosia}

The genus Coelosia is distinguished from other related genera by the following characters (Søli 1997): Frons bare, frontal tubercle simple and pointed. Labrum well developed, with or without setae. Third palpomere without distinct sensory pit. Mesopleuron, laterotergite and mediotergite all bare. Wing surface with small, irregularly arranged microtrichia only. Costa produced well beyond tip of $\mathrm{R}_{5}$. $\mathrm{Sc}_{1}$ usually with some setae, ending in costa. Neither $\mathrm{Sc}_{2}$ nor $\mathrm{R}_{4}$ present. Point of furcation of cubital fork distinctly beyond level of point of furcation of media; both cubital branches straight or nearly so. Tibiae with developed setae. Male gonostylus usually with distinct, well-developed interior appendage. 


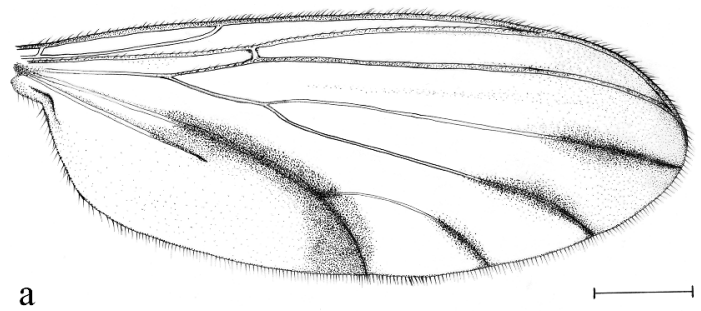

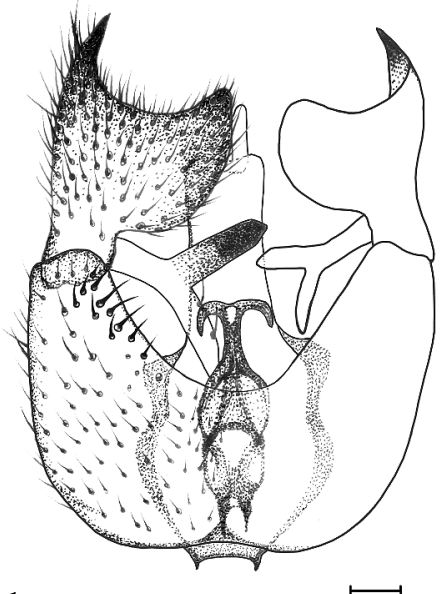

b

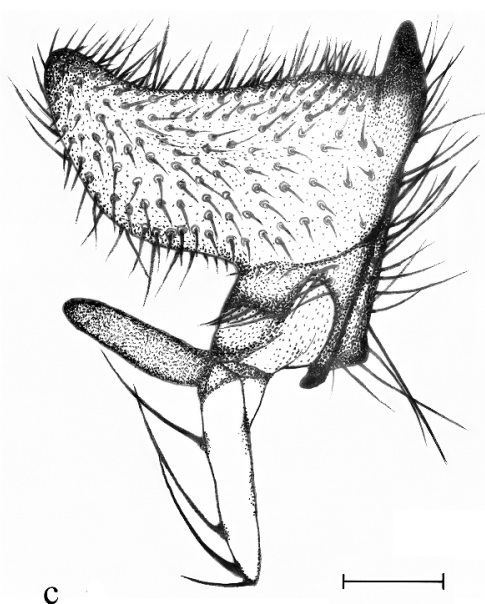

$\mathrm{c}$

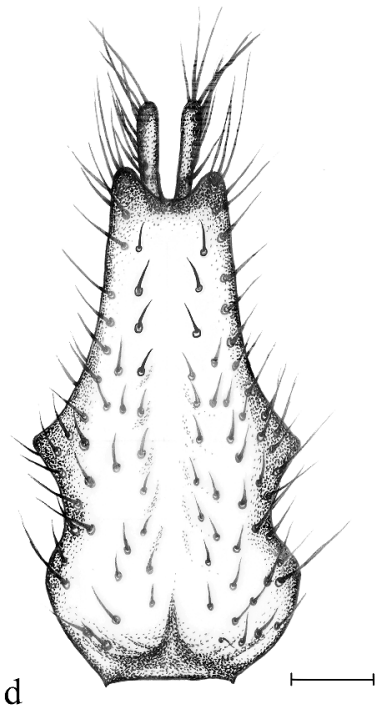

Fig. 1. Structures of male Coelosia tibetensis, sp. $\mathbf{n}$. - a. Wing. - b. Terminalia, ventral view. - c. Gonostylus, interior view. $-\mathrm{d}$. Tergite 9 and cerci, dorsal view. Scale bars, a: $1 \mathrm{~mm}$; b-d: $0.1 \mathrm{~mm}$.

\subsection{Description of Coelosia tibetensis Cao \& Huang, sp. n.}

Type material. Holotype $\widehat{\partial}$ (20100032). China, Tibet Autonomous Region, Chamdo Prefecture, Zhugu Temple, 9659'44'E, 315’31'N, 4,100 $\mathrm{m}$ a.s.1., 14.VIII.2010, Jian Cao leg. Paratypes $1 \jmath, 1$, with same data as holotype. All types deposited in the Insect Collection of Chongqing Three Gorges Vocational College, Wanzhou, Chongqing, P. R. China.

Description. Male (Fig. 1a-d). Lengths: body: $5.14 \mathrm{~mm}$; wing: $4.55 \mathrm{~mm}$.

Head. Yellowish brown. Two ocelli, median ocellus entirely reduced. Antennae: scape and pedicel cup-shaped, obscurely yellow. Flagellum: first flagellomere yellowish brown, obscurely yellow basally; remaining flagellomeres yellowish brown; terminal flagellomere with a small papilla. Palpi yellow to obscurely yellow, terminal palpomere long.

Thorax. Mesonotum brown, three separated conspicuous stripes on disc by one or two rows of dark brown bristles, median yellow stripe broad, extending anteriorly to pronotum, two admedian stripes. Scutellum brown with two strong bristles on posterior margin. Pleura and mediotergite black brown. Halter yellow.

Wings (Fig. 1a). Hyaline, with brown shading extending from middle of cubical to apex of $\mathrm{CuA}_{2}$, very faint brown shade present subapically on $\mathrm{M}_{1}, \mathrm{M}_{2}$ and $\mathrm{Cu} \mathrm{A}_{1}$. Costa, $\mathrm{R}_{1}$ and $\mathrm{R}_{5}$ with setae. Costa produced beyond tip of $R_{5}$, covering $1 / 2$ of distance to $\mathrm{M}_{1}$. Sc bare, ending in $\mathrm{C}$ slightly before Rs. $\mathrm{Sc}_{2}$ absent. Point of furcation of $\mathrm{M}$ slightly beyond the level of Rs; point of furcation $\mathrm{CuA}$ distinctly beyond the point of furcation of M.

Legs. Yellow, tibial spurs black. Fore basitarsus subequal in length to fore tibia, mid basitarsus $0.7 \times$ length of mid tibia, hind basitarsus $0.6 \times$ length of hind tibia. Claws minute.

Abdomen. Slender, clothed with many moderate setae. Tergite 1 dark brown, tergites 2 and 6 

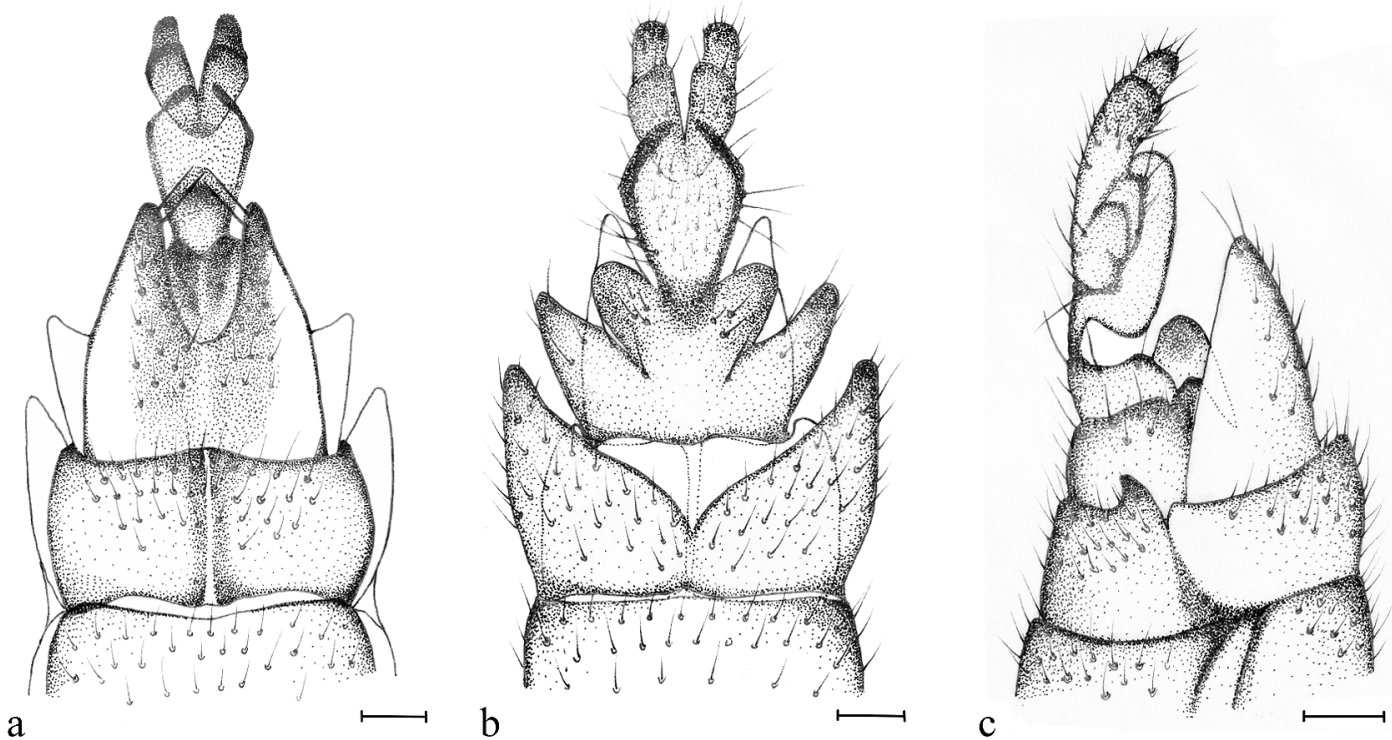

Fig. 2. Female Terminalia of Coelosia tibetensis, sp. n. - a. Ventral view. - b. Dorsal view. - c. Lateral view. Scale bars: $0.1 \mathrm{~mm}$.

dark brown, yellow on posterior fourth, tergites 3-5 dark brown, yellow on posterior half. Segments 7 and 8 strongly reduced, retractable. Terminalia not rotated.

Hypopygium (Fig. 1b-d). Brown, elongate. Tergite 9 elongated, about $2.0 \times$ as long as wide, with a bare stripe on medial area from base to apex. Cerci long, slender, separated. Gonocoxite fused along of $1 / 2$ length, with fine setae except medial border with black stout setae. Gonostylus well developed, bowl-shaped, basal 1/3 narrow, only the half width of apex, dorsal apex with one dark tooth, ventral apex blunt and round, many long bristles on dorsal side and many relatively short bristles on ventral side. Y-shaped interior appendage at the base of gonostylus yellow, except upward finger-like projection black-brown, bare, only downward projection with four very strong bristles. Aedeagus short, well sclerotized.

Female (antennae lost). Lengths: Body: 4.94 mm; wing: $4.38 \mathrm{~mm}$.

Colouration as in male, but abdominal tergite 1 dark brown, tergites 2-5 dark brown, yellow on posterior third, tergite 6 dark brown. Female terminalia in Fig. 2a-c.

Etymology. The name refers to the type locality: Tibet Autonomous Region.

Remarks. The new species is similar to
Coelosia distylata Søli, 1997 from Nepal in having two ocelli. However, it is easily distinguished by the outline of tergite 9 being elongated, about $2.0 \times$ as long as wide, with bare stripe on medial area from base to apex (about $1.7 \times$ as long as wide and without bare stripe in $C$. distylata). The shape of the gonostylus is also a good character to separate it from C. distylata (see Søli 1997: Fig. 15). Clear brown shadings on the wing (Fig. 1a) are peculiar and absent in C. distylata. Female terminalia are also different from those in $C$. distylata.

\section{Discussion}

So far, Coelosia tibetensis sp. n. is the second species in the genus Coelosia found in China. The first recorded species is Coelosia tenella (Zetterstedt, 1852) (Hackman et al. 1988). The specimens were collected from an altitude of 4,100 $\mathrm{m}$ in the eastern Tibetan Plateau, China. The discovery is encouraging. This new species and $C$. distylata both occur at high altitudes in the northern parts of the Oriental Region. This finding also confirms Søli's (1997) view that all southern records originate from high altitudes. We foresee that there are more species awaiting discovery in the Tibetan region of China. 
Acknowledgements. We thank our friends Huizhi Yang and Chunhua Wang for their help in collecting specimens. We gratefully acknowledge two anonymous referees for their critical review of the manuscript.

\section{References}

Hackman, W., Laštovka, P., Matile, L. \& Väisänen, R. 1988: Mycetophilidae. — In: Soós, Á. \& Papp, L. (eds), Catalogue of Palaearctic Diptera. Vol. 3, Ceratopogonidae - Mycetophilidae: 220-327. Budapest, Akadémiai Kiadó. 448 pp.
Søli, G. E. E., Vockeroth, J. R. \& Matile, L. 2000: 4. Families of Sciaroidea. - In: Papp, L. \& Darvas, B. (eds), Contributions to a Manual of Palaearctic Diptera (with Special Reference to Flies of Economic Importance): 49-92. Science Herald, Budapest. 604 p.

Søli, G. E. E. 1997: The systematics and phylogeny of Coelosia Winnertz, 1863 (Diptera, Mycetophilidae). — Entomologica scandinavica, Supplement 50: 57139.

Winnertz, J. 1863: Beitrag zu einer Monografie der Pilzmücken. - Verhandlungen zoologischen und botanischen Gesellschaft Wien 13: 637-964.

Zetterstedt, J. W. 1852: Diptera Scandinaviae. — Disposita et descripta 11: 4091-4545. Lundae. 